\title{
Correlation between the length of the pyloric cuff and postoperative evaluation after pylorus-preserving gastrectomy
}

\author{
Shinji Morita ${ }^{1}$, Mitsuru Sasako ${ }^{2}$, Makoto Saka $^{1}$, Takeo Fukagawa $^{1}$, Takeshi Sano $^{3}$, and Hitoshi Katai ${ }^{1}$ \\ ${ }^{1}$ Gastric Surgery Division, National Cancer Center Hospital, 5-1-1 Tsukiji, Chuo-ku, Tokyo 104-0045, Japan \\ ${ }^{2}$ Department of Surgery, Hyogo College of Medicine, Hyogo, Japan \\ ${ }^{3}$ Department of Gastroenterological Surgery, Cancer Institute Hospital, Japanese Foundation for Cancer Research, Tokyo, Japan
}

\begin{abstract}
Background. Recent years have seen the preserved pyloric cuff being lengthened in pylorus-preserving gastrectomy for early gastric cancer. We performed clinical assessment of the symptoms after pylorus-preserving gastrectomy in patients treated at the National Cancer Center Hospital in Japan during the past 9 years.

Methods. Four hundred and fifty-six patients who had undergone pylorus-preserving gastrectomy and been followed up for at least 3 years were studied. We classified the patients into two groups according to the length of the pyloric cuff (group A, within $3.0 \mathrm{~cm}$; group B, more than $3.0 \mathrm{~cm}$ ). Medical records were reviewed for further histological and follow-up data. A questionnaire regarding dumping syndrome and gastric stasis was also completed by the patients.

Results. Our results showed no statistically significant differences in symptoms, such as dumping syndrome or emptying disturbances, between the two groups.

Conclusion. Our study revealed that the differences in several functions and symptom scales were not pronounced between the two groups. Regardless of the length of the pyloric cuff, pylorus-preserving gastrectomy can be utilized for the treatment of early gastric cancer even if the tumor is located proximal to the middle body.
\end{abstract}

Key words Pylorus-preserving gastrectomy $\cdot$ Pyloric cuff $\cdot$ Late outcome $\cdot$ Dumping syndrome $\cdot$ Stasis

\section{Introduction}

A subtotal gastrectomy with D2 lymph node dissection has been the standard operation for early gastric cancer (EGC) located in the gastric middle body [1,2]. Patients with EGC have an excellent prognosis after surgical treatment, with 5-year survival rates being in excess of $90 \%$ [1-7]. In addition, the incidence of nodal involve-

Offprint requests to: $\mathrm{S}$. Morita

Received: October 13, 2009 / Accepted: February 15, 2010 ment from EGC is low, and involved lymph nodes are fundamentally confined to the perigastric area [7-9]. Therefore, Japanese surgeons have re-evaluated the treatment strategy of exclusive radical D2 gastrectomy for EGC and focused on function-preserving gastrectomy to attenuate postoperative symptoms such as weight loss, dumping syndrome, and residual gastritis caused by bile reflux, these being well known as frequent problems after subtotal gastrectomy.

Pylorus-preserving gastrectomy (PPG) is a modified distal gastrectomy for the treatment of gastric ulcers, designed by Maki et al. [10] in 1967 as a functionpreserving procedure. PPG is aimed at maintaining stomach capacity and reducing the amount of regurgitated duodenal juice by preserving the pyloric antrum. A limited lymph node dissection, as performed in the PPG operation, was shown to be a sufficiently safe and effective treatment for EGC by Kodama and Koyama in 1991 [11]. Since 1995, we have actively utilized PPG for the treatment of EGC in the middle body to minimize postoperative dysfunction in patients. Our recent study also showed the safety and radicality of PPG as a standard operation for EGC located in the middle body [12]. We have also reported that, as shown by the longterm follow-up results, PPG has clear advantages over distal gastrectomy with Billroth-I reconstruction, in terms of postoperative symptoms and functional outcomes [13].

Initially, the length of the preserved pyloric cuff was $1.5 \mathrm{~cm}$, as Maki et al. noted in the original article describing PPG [10]. Subsequently, Nakane et al. [14] reported that PPG with the transection of $2.5 \mathrm{~cm}$ proximal to the pyloric ring was superior to that with the transection of $1.5 \mathrm{~cm}$ in terms of some postoperative symptoms and weight recovery. Recently, Nunobe et al. [15] showed the low frequency of gastric stasis in patients with a $3-\mathrm{cm}$ length of pyloric cuff. Thus, in clinical practice, the length of the preserved pyloric cuff has tended to be increased, compared to that in the initial setting. By 
sparing the infrapyloric vessels, we have been able to preserve even longer pyloric cuffs in procedures performed at the National Cancer Center Hospital.

Against this background, we investigated the relationship between the length of the pyloric cuff and postoperative complications. We also assessed whether cuff length was associated with any differences in long-term symptoms more than 3 years' postoperatively, using questionnaires.

\section{Patients and methods}

\section{Subjects}

Between 1995 and 2003, 520 patients with apparent EGC underwent PPG with lymph node dissection and routine preservation of the suprapyloric area, the vagal nerve, the first branch of the right gastric artery, the pyloric sphincter, the celiac branch, and the infrapyloric vessels, as described previously [12]. During these operations, station No. 5 nodes are regularly inspected to exclude patients with gross metastasis (enlarged and/or hard nodes) in this region.

Thirty-four patients were excluded from the present study because of metachronous cancer. Four patients were excluded because of peritoneal and liver metastases. Fourteen patients died of other organ cancers or other causes and were also excluded. Three patients were excluded because additional gastrectomy was performed for residual cancers. One patient was excluded because he was followed up in other hospitals, two were excluded because of follow up at another division, and two were excluded because of mental illness. Four patients were excluded because of missing data. Thus, a total of 456 patients were enrolled in this study.

Questionnaires identifying postoperative symptoms were sent to the 456 patients after more than 3 years from the operation date. The response rate was $89.5 \%$. Data from a total of 408 patients were analyzed. These patients were divided into two groups based on the lengths of their preserved pyloric cuffs (Fig. 1). Of the 408 patients, 300 had a relatively short preserved pyloric cuff (within $3.0 \mathrm{~cm}$; group A) and 108 had a relatively long pyloric cuff (more than $3.0 \mathrm{~cm}$; group B).

\section{Methods}

Surgical specimens were examined and scored according to the Japanese classification of gastric carcinoma [16]. Medical records were reviewed for further histological and follow-up data. Long-term symptoms were assessed using the diagnostic criteria established by the Japanese Society of Gastroenterological Surgery and a postal survey. The questionnaire included a total of 38 items and was composed of four scales: evaluating early dumping symptoms (18 items), late dumping symptoms (5 items), emptying disturbances (9 items), and other data (6 items) such as oral intake, bowel movements, current weight, and satisfaction rate (Table 1). A higher mean value on the symptom scales corresponded to a higher symptomatology (0, "not at all"; 1 , "occasionally"; 2, "quite often"). The incidence of grade 2 symptoms was calculated. The patients underwent a gas-

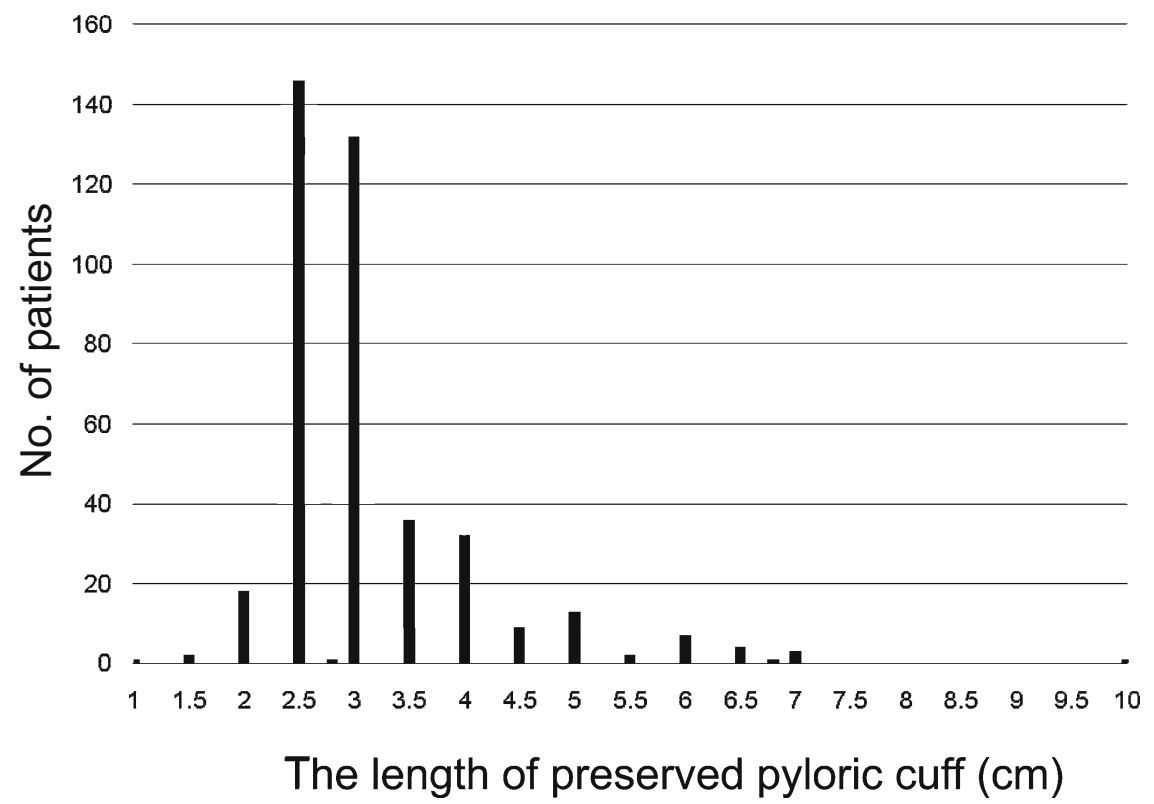

Fig. 1. Length distribution of the preserved pyloric cuff in pylorus-preserving gastrectomy. The cuff length means the length of the lesser curvature measured with a solid ruler during the operation. The median length of the preserved cuff was $3.0 \mathrm{~cm}$ (range, $1.0-10.0 \mathrm{~cm}$ ) 
Table 1. Questionnaire survey of postoperative symptoms ${ }^{\mathrm{a}}$

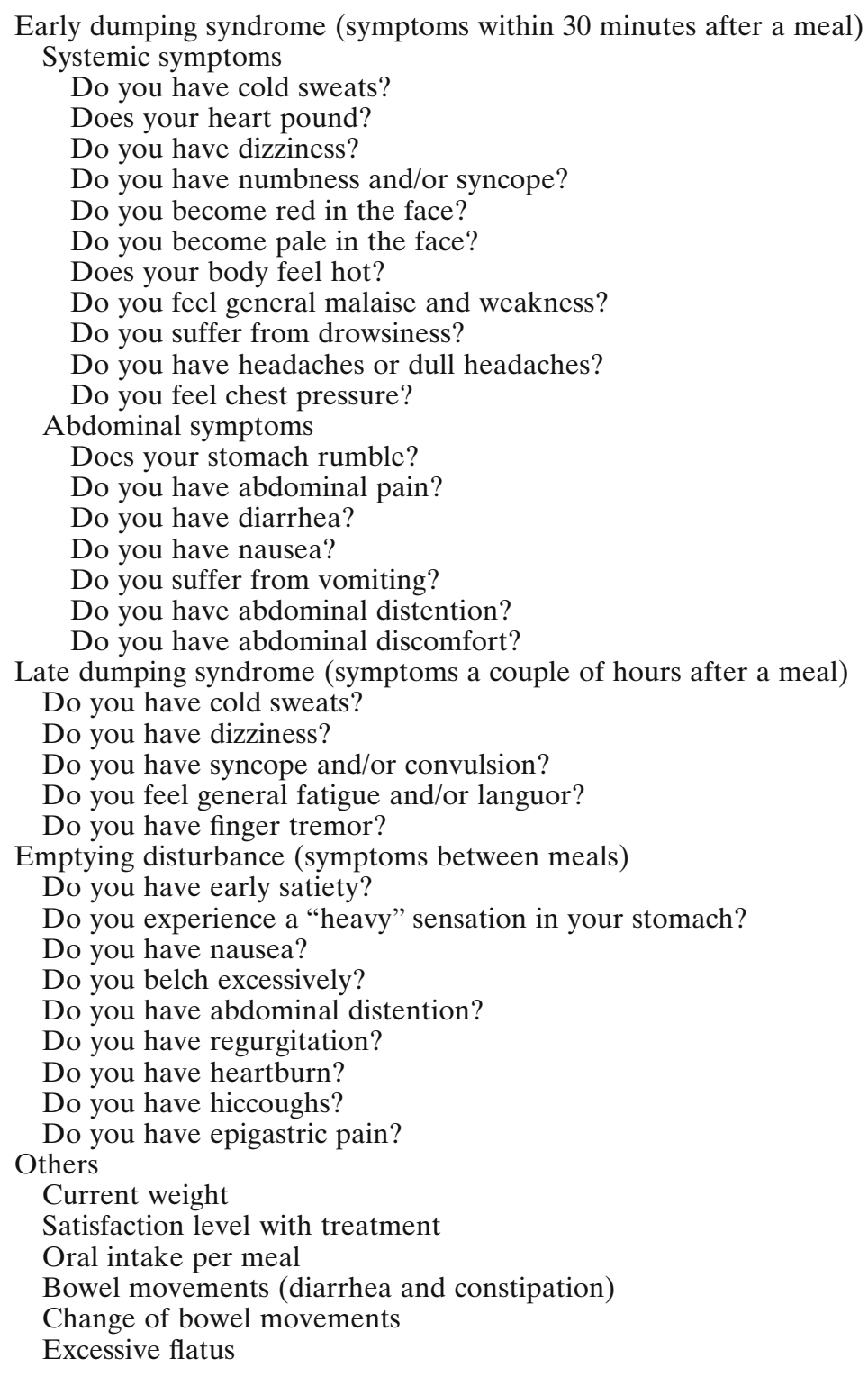

${ }^{\text {a }}$ Questionnaire created by the Japan Society of Gastrointestinal Surgery

trointestinal endoscopy examination at least once within 2 years after surgery. The postoperative state of the remnant stomach was evaluated more than 3 years postoperatively using the Residue, Gastritis, Bile (RGB) classification [17]. The incidences of reflux esophagitis with a Los Angeles classification of B or greater, remnant gastritis and residual food of grade 2 or greater, and bile reflux of grade 1 were regarded as meaningful findings. Unexamined patients and patients with missing data were excluded to calculate the incidence. An abdominal ultrasonography scan was performed more than 1 year after the operation. Patients with or without cholelithia- sis were examined. Patients who underwent a cholecystectomy either preoperatively or intraoperatively were excluded for the calculations of incidence.

\section{Data analysis}

Statistical analyses were performed using SPSS 14.0 software (SPSS, Chicago, IL, USA). Clinicopathological findings in the two groups were compared by using $t$-tests, the Mann-Whitney $U$-test, the $\chi^{2}$ test, and Fisher's exact test. Differences were considered significant at $P<0.05$. 


\section{Results}

\section{Patient characteristics and clinicopathological variables}

The baseline patient characteristics are summarized in Table 2. Questionnaires completed by 408 patients (mean age, 57.1 years; range, 27 to 86 years) were available for analysis. There was no age difference (mean ages of 56.6 and 58.7 years for groups $\mathrm{A}$ and $\mathrm{B}$, respectively; $P=0.087$ ). But the two groups differed in sex ratios. Half of the patients in group B were male, while group A was predominantly male $(64 \% ; P=0.013)$. The body mass index was around 23 in both groups.

As for the microscopic findings of the resected specimens, $388(95.1 \%)$ were confirmed to have EGCs (mucosa, 241; submucosa, 147) and 20 (4.9\%) were found to have more advanced tumors (muscularis propria, 14; subserosa, 6). Our data showed that the overall incidence of nodal involvement in all patients was $9.3 \%$ (38 patients). No differences in the distribution of the pathological depth of invasion and lymph node metastasis were observed between the two groups.

\section{Early outcomes (Table 3)}

The operation time was significantly longer for group B than for group A. Both groups had few complications, with the exception of gastric stasis that had severe symptoms requiring fasting and intravenous fluid support. Gastric stasis was observed in 30 of the 300 patients in group A $(10 \%)$ and in 8 of the 108 patients in group B $(7.4 \%)$. No difference in the incidence of postoperative complications was observed. No mortalities occurred in either group.

\section{Late outcomes (Tables 4,5)}

The incidence of dumping symptoms was low in both groups, especially in the late phase. On the other hand, emptying disturbances, including early satiety, a "heavy" sensation in the stomach, eructation, abdominal distention, and heartburn, were relatively frequent, occurring in approximately $6 \%-11 \%$ of the patients. No significant differences in the questionnaire responses were observed between the two groups. The mean relative body weight (current body weight/preoperative body

Table 2. Patients' characteristics and clinicopathological variables

\begin{tabular}{lcc}
\hline & $\mathrm{A}(n=300)$ & $\mathrm{B}(n=108)$ \\
\hline Age, in years ${ }^{\mathrm{a}}$ (range) & $56.6 \pm 10.6(27-82)$ & $58.7 \pm 11.9(31-86)$ \\
Sex (male/female) & $191 / 109$ & $54 / 54^{*}$ \\
Body mass index $^{\mathrm{a}}$ (range) & $23.0 \pm 3.0(14.9-32.4)$ & $23.1 \pm 2.8(16.2-28.8)$ \\
Depth of invasion (pathological) & & 54 \\
$\quad$ Mucosa & 187 & 46 \\
$\quad$ Submucosa & 101 & 5 \\
$\quad$ Muscularis propria & 9 & 3 \\
$\quad$ Subserosa & 3 & 100 \\
Lymph node metastasis & 270 & 8 \\
$\quad$ Node-negative & 30 & \\
$\quad$ Node-positive & & \\
$* P<0.05$ & & \\
${ }^{\mathrm{a}}$ Mean \pm SD & &
\end{tabular}

Table 3. Early outcomes including postoperative complications

\begin{tabular}{|c|c|c|c|}
\hline & $\mathrm{A}(n=300)$ & $\mathrm{B}(n=108)$ & $P$ value \\
\hline Mean duration of operation (min) & 193 (median, 191; range, 93-325) & 211 (median, 209; range, 125-318) & $<0.001$ \\
\hline Mean amount of bleeding (cc) & 264 (median, 216; range, 26-1989) & 278 (median, 254; range, 43-1340) & 0.196 \\
\hline \multicolumn{4}{|l|}{ Postoperative complications } \\
\hline Postoperative bleeding & $3(1.0)$ & $0(0)$ & 0.396 \\
\hline Anastomotic leak & $2(0.7)$ & $0(0)$ & 0.540 \\
\hline Intraabdominal abscess & $1(0.3)$ & $2(1.9)$ & 0.172 \\
\hline Gastric stasis & $30(10)$ & $8(7.4)$ & 0.427 \\
\hline Pancreatic fistula & $4(1.3)$ & $1(0.9)$ & 0.602 \\
\hline Atelectasis or pneumonia & $11(3.7)$ & $2(1.9)$ & 0.286 \\
\hline
\end{tabular}

Values in parentheses are percentages, unless otherwise indicated 
Table 4. Late outcomes including postoperative complications

\begin{tabular}{|c|c|c|c|}
\hline & $\mathrm{A}(n=300)$ & $\mathrm{B}(n=108)$ & $P$ value \\
\hline \multicolumn{4}{|l|}{ Early dumping syndrome } \\
\hline \multicolumn{4}{|l|}{ Systemic symptoms } \\
\hline Diaphoresis & $1(0.3)$ & $0(0)$ & 0.735 \\
\hline Pounding & $2(0.7)$ & $1(0.9)$ & 0.604 \\
\hline Dizziness & $1(0.3)$ & $1(0.9)$ & 0.460 \\
\hline Numbness and/or syncope & $2(0.7)$ & $1(0.9)$ & 0.604 \\
\hline Red in the face & $4(1.3)$ & $0(0)$ & 0.291 \\
\hline Pale in the face & $1(0.3)$ & $0(0)$ & 0.735 \\
\hline Hot flush & $4(1.3)$ & $1(0.9)$ & 0.605 \\
\hline Malaise and weakness & $4(1.3)$ & $0(0)$ & 0.291 \\
\hline Sleepiness & $13(4.3)$ & $5(4.6)$ & 0.541 \\
\hline Dull headache & $1(0.3)$ & $0(0)$ & 0.735 \\
\hline Chest pressure & $4(1.3)$ & $0(0)$ & 0.291 \\
\hline \multicolumn{4}{|l|}{ Abdominal symptoms } \\
\hline Borborygmi & $10(3.3)$ & $5(4.6)$ & 0.362 \\
\hline Abdominal pain & $3(1.0)$ & $0(0)$ & 0.396 \\
\hline Diarrhea & $10(3.3)$ & $5(4.6)$ & 0.362 \\
\hline Nausea & $2(0.7)$ & $1(0.9)$ & 0.604 \\
\hline Vomiting & $0(0)$ & $0(0)$ & - \\
\hline Abdominal distention & $24(8.0)$ & $9(8.3)$ & 0.913 \\
\hline Abdominal discomfort & $19(6.3)$ & $7(6.5)$ & 0.957 \\
\hline \multicolumn{4}{|l|}{ Late dumping syndrome } \\
\hline Cold sweat & $0(0)$ & $1(0.9)$ & 0.265 \\
\hline Dizziness & $0(0)$ & $0(0)$ & - \\
\hline Syncope and/or convulsion & $1(0.3)$ & $0(0)$ & 0.735 \\
\hline General fatigue and/or languor & $5(1.7)$ & $1(0.9)$ & 0.498 \\
\hline Finger tremor & $3(1.0)$ & $1(0.9)$ & 0.714 \\
\hline
\end{tabular}

Values in parentheses are percentages

Table 5. Late outcomes (symptom scores for gastric emptying and "others")

\begin{tabular}{|c|c|c|c|}
\hline & $\mathrm{A}(n=300)$ & $\mathrm{B}(n=108)$ & $P$ value \\
\hline \multicolumn{4}{|l|}{ Emptying disturbance } \\
\hline Early satiety & $26(8.7)$ & $12(11.1)$ & 0.454 \\
\hline "Heavy" sensation in stomach & $24(8.0)$ & $9(8.3)$ & 0.913 \\
\hline Nausea & $1(0.3)$ & $0(0)$ & 0.735 \\
\hline Eructation & $23(7.7)$ & $12(11.1)$ & 0.273 \\
\hline Abdominal distention & $22(7.3)$ & $7(6.5)$ & 0.768 \\
\hline Regurgitation & $12(4.0)$ & $3(2.8)$ & 0.406 \\
\hline Heartburn & $18(6.0)$ & $8(7.4)$ & 0.608 \\
\hline Hiccough & $4(1.3)$ & $2(1.9)$ & 0.502 \\
\hline Epigastric pain & $8(2.7)$ & $0(0)$ & 0.083 \\
\hline \multicolumn{4}{|l|}{ Other symptoms } \\
\hline Relative body weight ${ }^{\mathrm{a}}$ & $92.9 \pm 7.3$ (range, $60.1-110.3)$ & $91.7 \pm 7.5$ (range, $68.4-116.4)$ & 0.145 \\
\hline \multicolumn{4}{|l|}{ Current/preoperative (\%) } \\
\hline Satisfaction level with treatment & $(n=293)$ & $(n=105)$ & \\
\hline Unsatisfied & $6(2.0)$ & $1(1.0)$ & 0.407 \\
\hline Oral intake per meal compared with normal status & $(n=295)$ & $(n=108)$ & \\
\hline No change & $98(33.2)$ & $24(22.2)$ & 0.096 \\
\hline $50 \%$ or more & $161(54.6)$ & $67(62.0)$ & \\
\hline $50 \%$ or less & $36(12.2)$ & $17(15.7)$ & \\
\hline Bowel movements & $(n=295)$ & $(n=107)$ & \\
\hline Growing worse & $39(13.2)$ & $13(12.1)$ & 0.481 \\
\hline Flatulence compared with normal status & $(n=299)$ & $(n=108)$ & \\
\hline Increased and disabling & $7(2.3)$ & $2(1.9)$ & 0.557 \\
\hline
\end{tabular}

Values in parentheses are percentages, unless otherwise specified

${ }^{\text {a }}$ Mean \pm SD 
Table 6. Endoscopic findings in remnant stomach

\begin{tabular}{lccc}
\hline & A $(n=226)$ & B $(n=66)$ & $P$ value \\
\hline Esophagitis & $15(6.6)$ & $3(4.5)$ & 0.388 \\
Remnant gastritis & $23(10.2)$ & $5(7.6)$ & 0.528 \\
Residual food & $63(27.9)$ & $19(28.8)$ & 0.885 \\
Bile reflux & $25(11.1)$ & $6(9.1)$ & 0.647 \\
\hline
\end{tabular}

Values in parentheses are percentages

weight [\%]) was also similar in the two groups (92.9\% in group A and $91.7 \%$ in group B). The patient satisfaction level was also not significantly different between the groups. The number of patients who were dissatisfied with the treatment was $6(2.0 \%)$ in group A and 1 $(1.0 \%)$ in group B. As regards postoperative oral intake tolerated per meal, compared with normal, no change was reported by $33.2 \%$ of the patients in group A and $22.2 \%$ of the patients in group B. A postoperative intake of $50 \%$ or greater than the normal volume was reported by $54.6 \%$ of the patients in group A and $62.0 \%$ of the patients in group B. An intake of $50 \%$ or less than the normal volume was reported by $12.2 \%$ of the patients in group $\mathrm{A}$ and $15.7 \%$ of the patients in group B. This difference was not significant $(P=0.096)$. Both groups reported similar outcomes with regard to bowel movements and frequent flatus.

\section{Endoscopic findings (Table 6)}

No significant differences in esophagitis, remnant gastritis, residual food, or bile reflux were observed between groups $\mathrm{A}$ and $\mathrm{B}$.

\section{Abdominal ultrasound findings in the gallbladder}

Ultrasound findings showed no significant difference in the incidence of postoperative cholelithiasis. This condition was seen in $9.1 \%(22 / 242)$ in group A, compared with $8.4 \%(7 / 83)$ in group B.

\section{Discussion}

Among the limited options for the surgical treatment of EGC, PPG is the only one to have been proven to provide satisfactory digestive function $[12,13]$ according to the Japanese Gastric Cancer Association Guidelines for treatment of gastric cancer [18]. While PPG has several additional benefits, such as the prevention of dumping syndrome, regaining of weight, maintenance of pancreatic secretory function, prevention of duodenal juice reflux, and a low incidence of gallstones [19-22], it leads to the development of the characteristic postoperative symptom of delayed gastric emptying, at a constant rate $[20,21]$.
With regard to early outcomes in the present study, the length of the pyloric cuff influenced the operation time (Table 3), because preserving the infrapyloric vessels requires a meticulous operative technique based on thorough anatomical knowledge of the region surrounding the infrapyloric area. Our results also showed an extremely low incidence of postoperative complications, with the exception of gastric stasis. Gastric stasis, or emptying disturbance, is the most common complaint after PPG in the immediate postoperative period. One reason for the gastric stasis is the division of the antral intramural nerves, as described by Holle et al. [23]. Impaired circulation around the retained antrum, possibly as a result of anastomotic edema, might be another contributing factor [24]. Although a multivariate analysis did not show any significant differences between our two groups, the preservation of the infrapyloric vessels, which supply and drain the pyloric antrum, may be more important when the distal transection line is set further away from the pylorus ring.

No difference was seen between our two groups with regard to late outcome (Tables 4, 5). A slightly lower oral intake was seen in group B than in group A. It seems likely that two main factors are responsible: the volume and the shape of the remnant stomach, because a decreased residual volume will cause microgastria (because of the small gastric remnant) [17-19] and a decrease in the exocrine function of the fundus, because a broad segmentectomy can be detrimental to the secretion of pepsin, hydrochloric acid, and ghrelin [25-27]. These factors should be considered when determining the optimal proximal transection line.

In the present study, we got comparable results in groups $\mathrm{A}$ and $\mathrm{B}$ (with patients with a $3-\mathrm{cm}$ pyloric cuff being classified in group B). Our comparison did not show any significant differences between the two groups. It seems that there may be complex factors, such as neural damage and inadequate blood flow to the pylorus, or the setting of the proximal transaction line.

Finally, an accurate functional assessment of pyloric motility should be performed preoperatively as well as postoperatively, using methods such as questionnaire surveys, hormone mediated response assays, contrast studies, or scintigraphy, because postoperative gastric function is closely related to preoperative function [2830], and appropriate patient counseling regarding likely functional outcomes can then be undertaken.

In recent years, EGC has been estimated to account for more than $50 \%$ of all gastric cancers in Japan [31]. Endoscopic mucosal resection (EMR) is one of the accepted treatments for differentiated intramucosal cancers which arise from intestinal metaplasia and are associated with a minimal risk of regional lymph node metastasis and are seen mostly in the pyloric antrum [9]. Advanced endoscopic therapy in modern times has led 
to a decrease in the population receiving surgery for EGC in the lower part of the stomach, so that PPG is increasingly being performed in a relatively higher proportion of EGCs located in the middle stomach. The gender difference between the two groups in our study could be said to be a sign that the surgical therapeutic objective had shifted from the lower part to the middle part of the stomach. Therefore, an important issue is whether the scope of indications for PPG can be widened to include EGCs located high in the middle body. Whether EGC located high in the middle body is a candidate for PPG requires careful consideration, because the small capacity of the residual stomach in such cases may restrict food intake [30, 32, 33].

The postoperative outcomes in the present study were unaffected by the length of the retained antrum. PPG is a feasible procedure for the treatment of EGC even if the tumors are located in the proximal to middle body. Over the long term, an extreme reduction in the residual volume may result in microgastria, although patients seldom experience dumping symptoms.

\section{References}

1. Maruyama K, Okabayashi K, Kinoshita T. Progress in gastric cancer surgery in Japan and its limits of radicality. World J Surg 1987;11:418-25.

2. Okamura T, Tsujitani S, Korenaga D, Haraguchi M, Baba H, Hiramoto Y, et al. Lymphadenectomy for cure in patients with early gastric cancer and lymph node metastasis. Am J Surg 1988; 155:476-80.

3. Sue-Ling HM, Martin IG, Griffith J, Ward DC, Quirke P, Dixon MF, et al. Early gastric cancer: 46 cases treated in one surgical department. Gut 1992;33:1318-22.

4. Sue-Ling HM, Johnston D, Martin IG, Dixon MF, Lansdown MRJ, McMahon MJ, et al. Gastric cancer: a curable disease in Britain. BMJ 1993;307:591-6.

5. Kikuchi S, Katada N, Sakuramoto S, Kobayashi N, Shimao H, Watanabe M, et al. Survival after surgical treatment of early gastric cancer: surgical techniques and long-term survival. Langenbecks Arch Surg 2004;389:69-74.

6. Kunisaki C, Akiyama H, Nomura M, Matsuda G, Otsuka Y, Ono $\mathrm{H}$, et al. Surgical outcomes for early gastric cancer in the upper third of the stomach. J Am Coll Surg 2005;200:15-9.

7. Sano T, Sasako M, Kinoshita T, Maruyama K. Recurrence of early gastric cancer: follow up 1475 patients and review of the Japanese literature. Cancer 1993;72:3174-8.

8. Ikeda Y, Saku M, Kishihara F, Maehara Y. Effective follow-up for recurrence or a second primary cancer in patients with early gastric cancer. Br J Surg 2005;92:235-9.

9. Gotoda T, Yanagisawa A, Sasako M, Ono H, Nakanishi Y, Shimoda $\mathrm{T}$, et al. Incidence of lymph node metastasis from early gastric cancer: estimation with a large number of cases at two large centers. Gastric Cancer 2000;3:219-25.

10. Maki T, Shiratori T, Hatafuku T, Sugawara K. Pylorus-preserving gastrectomy as an improved operation for gastric ulcer. Surgery 1967;61:838-45.

11. Kodama M, Koyama K. Indications for pylorus preserving gastrectomy for early gastric cancer located in the middle third of the stomach. World J Surg 1991;15:628-33.
12. Morita S, Katai H, Saka M, Fukagawa T, Sano T, Sasako M. Outcome of pylorus-preserving gastrectomy for early gastric cancer. Br J Surg 2008;95:1131-5.

13. Nunobe S, Sasako M, Saka M, Fukagawa T, Katai H, Sano T. Symptom evaluation of long-term postoperative outcomes after pylorus-preserving gastrectomy for early gastric cancer. Gastric Cancer 2007;10:167-72.

14. Nakane Y, Michiura T, Inoue K, Sato M, Nakai K, Yamamichi K. Length of the antral segment in pylorus-preserving gastrectomy. Br J Surg 2002;89:220-4.

15. Nunobe S, Hiki N, Fukunaga T, Tokunaga M, Ohyama S, Seto Y, et al. Laparoscopy-assisted pylorus-preserving gastrectomy: preservation of vagus nerve and infrapyloric blood flow induces less stasis. World J Surg 2007;31:2335-40.

16. Japanese Gastric Cancer Association. Japanese classification of gastric carcinoma - 2nd English edition -. Gastric Cancer 1998; 1:10-24.

17. Kubo M, Sasako M, Gotoda T, Ono H, Fujishiro M, Saito D, et al. Endoscopic evaluation of the remnant stomach after gastrectomy: proposal for a new classification. Gastric Cancer 2002; 5:83-9.

18. Japanese Gastric Cancer Association. Guidelines for treatment of gastric cancer. 2nd ed. Japanese Gastric Cancer Association, Tokyo; 2004.

19. Nishikawa K, Kawahara H, Yumiba T, Nishida T, Inoue Y, Ito T, et al. Functional characteristics of the pylorus in patients undergoing pylorus-preserving gastrectomy for early gastric cancer. Surgery 2002;131:613-24.

20. Nakabayashi T, Mochiki E, Garcia M, Haga N, Suzuki T, Asao T, et al. Pyloric motility after pylorus-preserving gastrectomy with or without the pyloric branch of the vagus nerve. World J Surg 2002;26:577-83.

21. Nakane Y, Akehira K, Inoue K, Iiyama H, Sato M, Masuya Y, et al. Postoperative evaluation of pylorus-preserving gastrectomy for early gastric cancer. Hepatogastroenterology 2000;47:5905.

22. Toshinaga N, Shunichi T, Hiroyuki K, Zhou-Lu D, Kazunori Y, Kazuo C, et al. Effect of prepyloric gastric transection and anastomosis on sphincter of Oddi cyclic motility in conscious dogs. J Gastroenterol 2001;36:530-7.

23. Holle GE, Steinbach E, Forth W. Intrinsic corporoantropyloric coordination of motility and gastric emptying. Am J Physiol 1994;266:G255-62.

24. Bar-Natan M, Larson GM, Stephnes G, Massey T. Delayed gastric emptying after gastric surgery. Am J Surg 1996;172:248.

25. Sekine K, Sato T, Maki T, Shiratori T. Pylorus-preserving gastrectomy for gastric ulcer-one nine-year follow-up study. Surgery 1975;77:92-9.

26. Kojima M, Hosoda H, Date Y, Nakazato M, Matsuo H, Kangawa $\mathrm{K}$. Ghrelin is a growth-hormone-releasing acylated peptide from stomach. Nature 1999;402:656-60.

27. Nakazato M, Murakami N, Date Y, Kojima M, Matsuo H, Kangawa $\mathrm{K}$, et al. A role for ghrelin in the central regulation of feeding. Nature 2001;409:194-8.

28. Urushihara T, Sumimoto K, Shimokado K, Kuroda Y. Gastric motility after laparoscopically assisted distal gastrectomy, with or without preservation of the pylorus, for early gastric cancer, as assessed by digital dynamic X-ray imaging. Surg Endosc 2004; 18:964-8.

29. Michiura T, Nakane Y, Kanbara T, Nakai K, Inoue K, Yamamichi $\mathrm{K}$, et al. Assessment of the preserved function of the remnant stomach in pylorus-preserving gastrectomy by gastric emptying scintigraphy. World J Surg 2006;30:1277-83.

30. Iezato H, Ohya T, Ohwada S, Itagaki S, Yokomori T, Morishita Y. Jejunal pouch interposition with an antiperistaltic conduit as a pyloric ring substitute after standard distal gastrectomy: a comparison with the use of an isoperistaltic conduit. Hepatogastroenterology 2000;47:756-60. 
31. Maruyama K, Kaminishi M, Hayashi K, Isobe Y, Honda I, Katai $\mathrm{H}$, et al. Gastric cancer treated in 1991 in Japan: data analysis of nationwide registry. Gastric Cancer 2006;9:51-66.

32. Tomita R, Takizawa H, Tanjoh K. Physiological effects of cisapride on gastric emptying after pylorus-preserving gastrectomy for early gastric cancer. World J Surg 1998;22:35-40.
33. Ohya T, Ohwada S, Iesato H, Takeyoshi I, Kawashima Y, Ogawa $\mathrm{T}$, et al. Jejunal pouch interposition after pylorus-preserving gastrectomy. J Surg Res 1999;86:177-82. 